\title{
Public perceptions of Australia's doctors, hospitals and health care systems
}

\author{
Elizabeth A Hardie and Christine R Critchley
}

T rust is crucial in medical settings, ${ }^{1}$ yet recent reports describe a decline in trust in Western health care systems ${ }^{2}$ and international health agencies. ${ }^{3}$ Waning medical trust in the United Kingdom permeates both public and private health sectors, ${ }^{4}$ while trust decrements in the United States reflect a privatised health industry. ${ }^{5}$ Australia's health care system has evolved over time to meet growing demands, and Australians have been increasingly encouraged to use private insurance to subsidise the escalating costs of public health care. ${ }^{6}$ It is not clear if this change has eroded public trust, because there are few published scientific data on Australians' trust in their health care providers and institutions.

The Swinburne National Technology and Science Monitor (SNTSM) ${ }^{7}$ has for several years assessed public perceptions of trust in various Australian institutions, including hospitals. Over the years, average ratings for hospitals have varied slightly, ranging from 3.3 to 3.6 out of 5 , indicating moderately high trust. In 2007, the SNTSM assessed trust in medical specialists and family doctors. Results showed that Australians had strong trust in their family doctors (mean, 4.1). Trust in specialists (mean, 3.8) and hospitals (mean, 3.6) was lower, but still fairly strong. ${ }^{7}$

To obtain a more detailed picture of Australians' views on their health care providers, institutions and systems, we conducted another national survey in 2007 . In addition to assessing trust in family doctors, specialists, alternative practitioners, public and private hospitals, private health insurers and Medicare, we also measured attitudes towards Australia's current health care system and the alternatives of a more universal taxpayer-funded public system and a more elite, user-pays private system.

\section{METHODS}

\section{Survey design and sampling strategy}

As part of a larger survey on the use of new technologies to promote health and prevent illness, 8 800 Australian adults participated in a computer-assisted telephone interview (CATI) in August 2007. The sample size was chosen to achieve an acceptable margin of

\section{ABSTRACT}

Objective: To assess public perceptions of Australia's doctors, hospitals and health care systems.

Design and participants: A cross-sectional national telephone survey of a random sample of 800 Australian adults in August 2007.

Main outcome measures: Ratings of subjective trust in health care providers, public and private hospitals, private health insurers and Medicare; attitudinal ratings for the current health care system, and public and private health care systems.

Results: Australians reported high trust in doctors (general practitioners more than specialists), low trust in alternative practitioners, moderate trust in hospitals (private more than public), and greater trust in Medicare than in private health insurers. Older adults had the greatest trust in physicians, hospitals and Medicare, but all age groups held similar attitudes toward public and private health care systems. Support for the current health care system with its mix of public and private funding was moderately strong, but all respondents reported weak pro-private attitudes and very strong pro-public attitudes.

Conclusions: Public perceptions of Australian medical professionals, institutions and systems are generally positive. This sample did not endorse an individual user-pays private health system, but strongly favoured a universal public health system that is collectively funded by the public purse.

MJA 2008; 189: 210-214

error (3.39\%) and confidence intervals of $95 \%$, assuming a $50 \%$ split on each question. ${ }^{9}$ Telephone numbers were randomly selected from the electronic white pages across all states and territories. Englishspeaking residents over 18 years of age were eligible to participate.

\section{Ethics approval}

The Swinburne University Human Research Ethics Committee approved this study.

\section{Survey instrument}

The survey included questions about the respondents' level of private health cover (none, hospital, extras, both), subjective health status (five-point rating: $1=$ unwell, to 5 =very healthy), frequency of visits to health professionals (weekly, monthly, 3monthly, 6-monthly, yearly, less), health care industry work experience (ever, never), demographic information, and sets of trust and attitude ratings.

Seven single-item trust ratings were used to assess two health systems (Medicare and private health insurance companies), two types of hospitals (public and private) and three types of health care professionals (the participant's own family doctor or general practitioner, medical specialists, and alternative practitioners [eg, naturopaths, acupuncturists]). Each target was rated on a sixpoint scale $(0=$ no trust at all, to $5=$ a great deal of trust).

Seven attitude items were rated on a sixpoint scale $(0=$ strongly disagree, to $5=$ strongly agree). One item assessed level of support for the current health care system or status quo ("I'm happy with the way Australia's current health care system is funded by a mix of public funds and private health insurance"). The other six items assessed preferences for public and private health care systems.

The sample was compared with the general population using Australian Bureau of Statistics (ABS) 2006 census data for all demographic factors except private health cover, which was compared with 2004 ABS data.

\section{Statistical analysis}

Psychometric analysis of attitude ratings was conducted with LISREL, version 8.54 (Scientific Software International, Chicago, Ill, USA). Sample weighting and descriptive and comparative analyses, including $\chi^{2}$ analysis, correlations, and within- and between- 
groups analysis of variance and covariance, were conducted using SPSS, version 15 (SPSS Inc, Chicago, Ill, USA).

\section{RESULTS}

CATI response rates were calculated according to the American Association for Public Opinion Research definitions. ${ }^{10}$ Of 7409 phone calls, 800 interviews were completed. Taking known (eg, refusals, under 18 years old) and unknown (eg, no answer, phone line disconnected) eligibility into account, the minimum response rate was $15.5 \%$ (maximum, 20.5\%) and the cooperation rate was $29.6 \%$ (maximum, 31.8\%). The mean interview time was 13.7 minutes (SD, 3.9 minutes).

\section{Psychometric properties of attitude ratings}

The factor structure of the six public and private health care attitude items was assessed using confirmatory factor analysis. A two-factor model yielded a good fit, and all factor loadings were significant $\left(\chi_{6}^{2}=29.64\right.$; $P<0.001$; comparative fit index, 0.96; adjusted goodness-of-fit index, 0.95; rootmean-square error of approximation, 0.08 [90\% CI, 0.05-0.10]).

The "pro-private" factor included the items: "Australia should adopt a private, userpays system like they have in the US" $(\lambda=0.69)$, "I would be willing to pay higher private health insurance premiums to improve my own health care services" $(\lambda=0.30)$, and "The very best health care should be available only to those who can afford it" $(\lambda=0.62)$.

The "pro-public" factor included the items: "I would be willing to pay higher taxes to improve Australia's health care services" $(\lambda=$ 0.86), "Australia should adopt a collective social health system supported by higher taxes as is done in some Scandinavian countries" $(\lambda=$ 0.57 ), and "There should always be a safety net of basic health care available to disadvantaged people who cannot afford to pay for it" $(\lambda=0.16)$. This latter item showed a negative cross-loading on the pro-private factor $(\lambda=-0.36, P<0.05)$ and the model included one significant correlated error variance between the two items representing a willingness to pay higher taxes and higher insurance premiums (Pearson's $r=0.29$ ).

Two composite total scores were computed from each item's factor score regression weight (FRW). Confirmatory congeneric measurement models ${ }^{11}$ were calculated to obtain separate FRWs for proprivate and pro-public factors. Each item was multiplied by its FRW, then proportionally summed to obtain total scores. Internal consistency $\left(r_{c}\right)$ coefficients ${ }^{11}$ showed acceptable reliability for pro-private $(0.65)$ and pro-public (0.95) attitudes.

\section{Demographic data}

The sample was representative of the Australian population in terms of education and health cover, but did not match the population distribution on age, sex or state/territory (all $\chi^{2}$ comparisons, $P<0.05$ ). Respondents' ages ranged from 18 to 91 years (mean [SD], 53.3 [16.7] years). Using four age groupings (18-37, 38-57, 58-77, $\geqslant 78$ years), the sample was representative of the 38-57years $(n=316)$ and $\geqslant 78$-years $(n=55)$ age groups, but younger adults (18-37 years; $n=138$ ) were under-represented, and older adults (58-77 years; $n=269$ ) were over-represented. Twelve respondents refused to give their age.

There was an imbalance by sex, with more women (63.25\%) than men (36.75\%) in the sample compared with the population ratio. When compared with state/territory populations, New South Wales, Victoria and Queensland were under-represented, while Western Australia, South Australia, Tasmania, the Australian Capital Territory and the Northern Territory were over-represented.

To account for these sampling errors, the data were weighted according to ABS proportions for age groups, sex and location for all further analyses. The weighted sample size was 740 , but numbers vary slightly between analyses due to missing data for some ratings.

\section{Trust and attitude ratings}

Analyses of trust and attitude ratings are based on weighted responses. Differences between weighted and unweighted means were negligible (range, 0.00-0.07).

Preliminary comparisons found no significant differences in mean trust or attitude ratings based on state/territory, sex, or health care industry experience, with two exceptions. Significant differences $(P<0.05)$ with negligible effect sizes $\left(\eta^{2}<0.02\right)$ were found for two targets based on sex, or health care industry experience: women reported higher trust in alternative practitioners than did men; and respondents who had worked in the health care industry reported less trust in private hospitals than those who had not (Box 1).

Apart from pro-private attitudes, and trust in alternative practitioners in the $\geqslant 78$-years age group, all means were well above the scale mid-point of 2.5 (Box 2). The sample reported high trust in their GPs and in specialists, and moderately high trust in private hospitals, public hospitals and Medicare. Moderately low trust was reported for private health insurers and alternative practitioners. Attitudes toward Australia's current health care system were moderately positive; pro-public attitudes were high and pro-private attitudes were very low.

A within-subject analysis of variance showed that trust ratings were significantly different across the seven types of practitioners and health systems $\left(P<0.05, \eta^{2}=0.22\right)$. Contrasts showed that all medical doctors were trusted more than alternative practitioners (GPs: $\eta^{2}=0.46$; specialists: $\eta^{2}=0.34$ ), but there was greater trust in GPs than specialists $\left(\eta^{2}=0.08\right)$. Medicare was trusted more than private health insurers $\left(\eta^{2}=0.07\right)$, and private hospitals were trusted more than public hospitals $\left(\eta^{2}=0.11\right)$.

Within-subject comparisons of the three attitude scores showed significant differences $\left(P<0.05, \eta^{2}=0.48\right)$. Contrasts revealed that pro-public attitudes were favoured more than the status quo $\left(\eta^{2}=0.01\right)$, but the status quo was greatly favoured over pro-private attitudes $\left(\eta^{2}=0.61\right)$. There was very strong endorsement of pro-public over pro-private attitudes $\left(\eta^{2}=0.62\right)$.

\section{Age differences in trust and attitude ratings}

Significant age effects were found for trust in all practitioners and institutions, apart from private health insurers (Box 2). Polynomial contrasts revealed linear effects for trust in GPs, public hospitals, Medicare, and alternative health practitioners. Older Australians reported greater trust in GPs, public hospitals and Medicare, but lower trust in alternative health practitioners. While there was not a significant linear effect for trust in medical specialists, post-hoc comparisons suggested that the older 58-77-years age group reported greater trust in specialists than did the 18-37-years age group.

Older age was associated with poorer selfreported health status (Spearman's rho $[\rho]=$ $-0.18, P<0.05)$ and more frequent health care visits $(\rho=0.10, P<0.05)$, while frequent health visits were associated with greater trust in private hospitals $(r=0.10$, $P<0.05)$. After controlling for the effects of health status and health visits, the pattern of age differences in trust and attitude ratings remained. The one exception was that trust in private hospitals did not differ by age group when the covariates were included $\left(P>0.05, \eta^{2}=0.01\right)$, suggesting that older 


\section{Demographic details of the sample, with weighted means (SDs) for trust and attitude ratings}

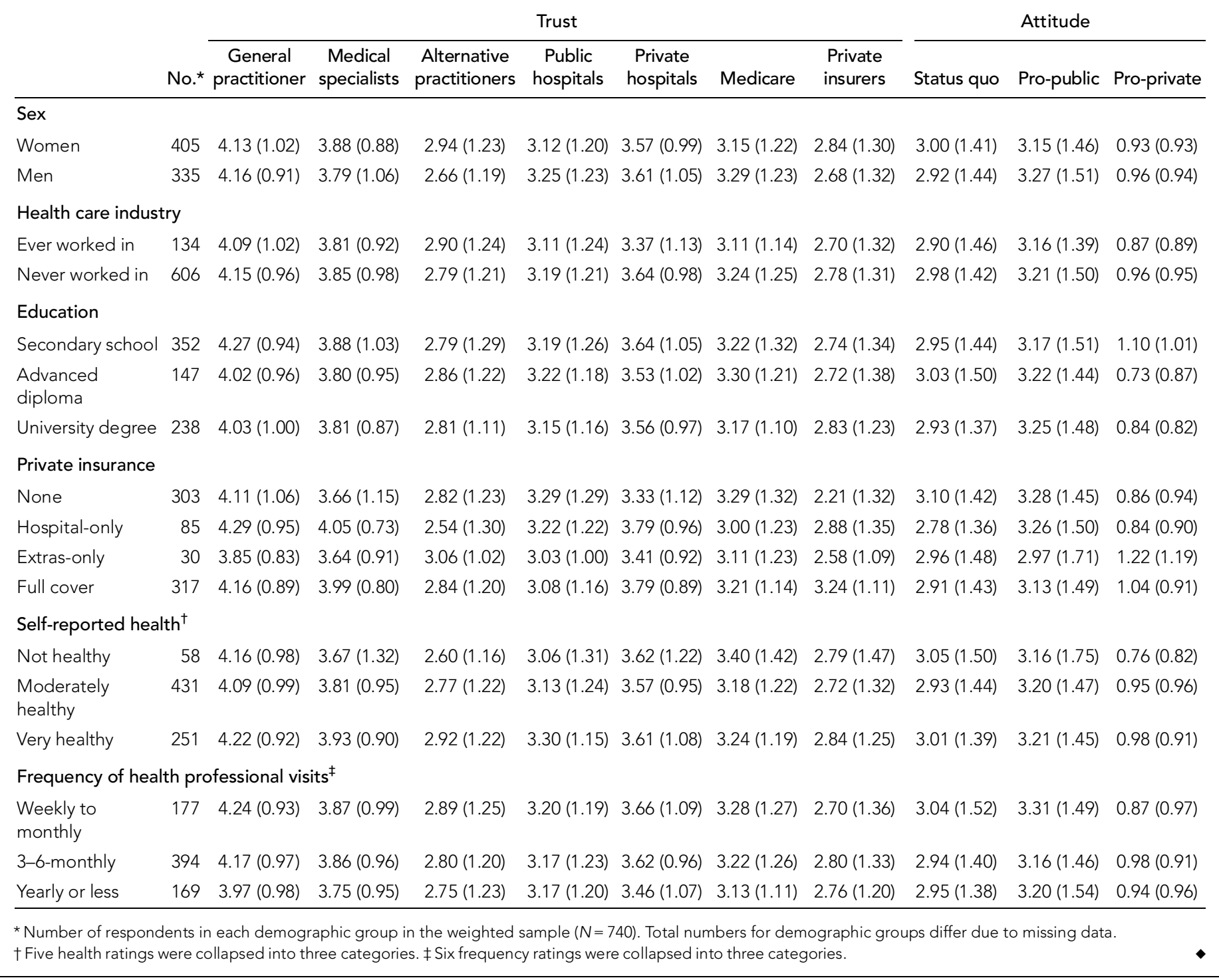

respondents' higher trust in private hospitals could be due to their greater need for and use of health care.

Older and younger Australians did not differ in attitudes to public or private health care systems. However, there was a slight age effect for attitudes toward the status quo $\left(\eta^{2}=\right.$ 0.01). Older Australians were more favourable towards the current system (Box 2), but neither contrasts nor post-hoc comparisons reached statistical significance.

\section{Education differences in trust and attitude ratings}

Education level was not associated with trust in health practitioners or systems, with one exception. There was a significant linear trend for trust in GPs, whereby those with secondary school education reported higher trust than did those with advanced diplomas or university degrees $\left(P<0.05, \eta^{2}=0.02\right)$ (Box 1). Similarly, groups based on education level did not differ in attitudes towards the current health system or pro-public attitudes; however, stronger pro-private attitudes were reported by those with secondary qualifications than the advanced diploma group and the university-educated $\left(P<0.05, \eta^{2}=0.03\right)($ Box 1$)$.

\section{Private health cover differences in trust and attitude ratings}

Comparisons of those with no private health insurance, hospital-only, extras-only and full cover (hospital and extras) showed that level of health cover was not associated with trust in GPs, alternative practitioners, public hospitals or Medicare. Differences were found for trust in specialists $\left(\eta^{2}=\right.$ 0.04) and private hospitals $\left(\eta^{2}=0.07\right)$ (Box 1). Those with hospital-only cover reported greater trust in specialists than did those with no private insurance. Those with hospital-only or full cover were more likely than those with no private insurance to trust private hospitals. Trust in private health insurers was highest among those with full cover and hospital-only cover, followed by those with extras-only and no cover. No health cover effects were found for pro-public attitudes or support for the current system; however, significant differences were evident for pro-private attitudes $\left(\eta^{2}=0.02\right)$. Those with full private cover had stronger pro-private attitudes than those with no private cover (Box 1). 


\section{Weighted means $(95 \% \mathrm{Cls})$ for trust and attitude ratings across total sample and age groups}

Total sample $(N=730)^{\star} \quad 18-37$ years $(n=228) \quad 38-57$ years $(n=292) \quad 58-77$ years $(n=168) \quad \geqslant 78$ years $(n=42)$

\begin{tabular}{|c|c|c|c|c|c|}
\hline \multicolumn{6}{|l|}{ Trust } \\
\hline General practitioner & $4.13(4.06-4.20)$ & $4.13(4.01-4.25)$ & $4.00(3.87-4.12)$ & $4.24(4.11-4.38)$ & $4.64^{\dagger}(4.44-4.84)$ \\
\hline Medical specialists & $3.83^{\ddagger}(3.76-3.91)$ & $3.75(3.62-3.87)$ & $3.78(3.66-3.90)$ & $4.03^{\S}(3.90-4.16)$ & 3.89 (3.54-4.24) \\
\hline Private hospitals & $3.58^{\ddagger}(3.51-3.66)$ & $3.72(3.60-3.84)$ & $3.44^{\S \uparrow}(3.31-3.57)$ & $3.58(3.40-3.75)$ & $3.88^{* * \uparrow}(3.61-4.16)$ \\
\hline Public hospitals & $3.18^{\ddagger}(3.09-3.27)$ & $3.23(3.08-3.38)$ & $3.06(2.91-3.21)$ & 3.19 (2.99-3.39) & $3.72^{\star \star}(3.46-3.99)$ \\
\hline Medicare & $3.20(3.11-3.30)$ & $3.20(3.05-3.36)$ & $3.08(2.94-3.23)$ & $3.26(3.06-3.46)$ & $3.83^{\star \star}(3.55-4.11)$ \\
\hline Private insurers & $2.76^{\ddagger}(2.66-2.86)$ & $2.68(2.52-2.83)$ & $2.66(2.49-2.82)$ & $2.98(2.77-3.19)$ & $3.09(2.64-3.54)$ \\
\hline Alternative practitioners & $2.81(2.72-2.90)$ & $2.94(2.79-3.09)$ & $2.86(2.73-3.00)$ & $2.66(2.45-2.87)$ & $2.26^{\S}(1.72-2.79)$ \\
\hline \multicolumn{6}{|l|}{ Attitude } \\
\hline Pro-public & 3.18 (3.07-3.29) & $3.14(2.95-3.33)$ & $3.14(2.96-3.33)$ & $3.25(3.03-3.47)$ & $3.41(3.00-3.82)$ \\
\hline Status quo & $2.96^{\ddagger}(2.85-3.06)$ & $3.04(2.86-3.22)$ & $2.75(2.58-2.92)$ & $3.10(2.87-3.32)$ & $3.34(2.94-3.74)$ \\
\hline Pro-private & $0.94^{\ddagger}(0.87-1.01)$ & $0.97(0.86-1.09)$ & $0.92(0.80-1.03)$ & $0.85(0.71-0.99)$ & $1.35(0.96-1.75)$ \\
\hline
\end{tabular}

\section{DISCUSSION}

This sample of Australians reported fairly high levels of trust in their health care providers, hospitals and systems, confirming that there is a good deal of public confidence in Australian health care.

Few studies have assessed public trust in health care providers and systems. Two notable exceptions are the 2007 SNTSM $^{7}$ Australian survey and recent European research comparing medical trust in the UK, the Netherlands and Germany. ${ }^{12}$ That research found that UK respondents had greater trust in family doctors and specialists than did Dutch or German respondents, but all reported strong trust in doctors, followed by moderately strong trust in hospitals. Our results mirrored the European ${ }^{12}$ findings and were consistent with the earlier $\mathrm{SNTSM}^{7}$ findings.

In our study, respondents' GPs were deemed more trustworthy than specialists or hospitals, but all medical practitioners and hospitals were trusted more than alternative practitioners. The sample as a whole had fairly low trust in these non-traditional practitioners, but they were trusted more by women than men. Others have shown that those who use alternative medicine are more likely to be women, ${ }^{13-15}$ people who suffer from chronic physical and psychological conditions, ${ }^{14,16}$ and those with a positive approach to preventive health care. ${ }^{13,14}$

We found that older age was associated with poorer self-reported health and more frequent health care visits, as well as stronger trust in doctors, hospitals and Medicare. It could be surmised that older adults were more trusting because of their health problems and dependence on health care providers. However, when health status and health visits were controlled for, age differences remained for all trust ratings except trust in private hospitals. This suggests that older Australians' greater need for health services may partly account for their greater trust in private hospitals, but did not influence their strong trust in doctors, public hospitals or Medicare. Unlike recent British research, ${ }^{17}$ which found that poorer health was associated with less trust in the health care system, older Australians with health problems seemed to maintain their trust in the public health system.

The sample had greater trust in private compared with public hospitals, but greater trust in public (Medicare) than private (health insurers) systems. This may reflect Australians' historical support for a public health care system, ${ }^{18}$ combined with an awareness of the long waiting lists and strained resources currently experienced by Australia's public hospitals. This pattern was evident even for respondents with private health cover, although they did show slightly greater trust in the private system than those without cover.

This Australian sample strongly endorsed the current health system, and had fairly weak pro-private attitudes and strong propublic attitudes. Individuals with full-cover private insurance held the strongest pro- private attitudes. Attitudes were not influenced by age, but education played a role, with the least-educated holding the strongest pro-private attitudes. Differences between a positive attitude to the status quo, strong pro-public attitudes and weak proprivate attitudes were accompanied by particularly strong effect sizes $\left(\eta^{2}>0.60\right)$. These findings demonstrate a striking preference for public over private health care, with the sample clearly favouring an improved public health care system supported by the public purse. Although the current system with its mix of public funds and private insurance was endorsed, this group of Australians was more likely to favour a collective, socially responsive health care system. A US-style user-pays private system was clearly not supported.

It should be noted that this study and recent European studies ${ }^{12,17}$ share a methodological limitation, in that trust was measured with single-item ratings. Such measures can be criticised because their validity and reliability are not readily evaluated. ${ }^{19}$ Nonetheless, single-item ratings are widely used in social surveys and seem to adequately capture general levels of trust that can be compared across targets and populations. ${ }^{7,12}$

This national survey confirmed that public trust in Australian health care is quite robust. There was strong trust in medical practitioners and mixed views on hospitals, with private hospitals currently trusted over public hospitals. Australians endorse the current 
Medicare system, but overwhelmingly favour a more socially responsive public health system, funded by the public purse, to provide quality care for all. These findings support a mandate for a more socially equitable health care system in Australia.

\section{ACKNOWLEDGEMENTS}

This research was supported by a Swinburne University Research Development Grant to Elizabeth Hardie for a research project on social trust. The university had no role in the study design, analysis, interpretation or writing of this article. We would like to thank the Australian Centre for Emerging Technologies and Society for access to the 2007 SNTSM data. We would also like to thank Peter Groenewegen of the Netherlands Institute for Health Services Research for providing us with the mean medical trust scores for their European samples.

\section{COMPETING INTERESTS}

None identified.

\section{AUTHOR DETAILS}

Elizabeth A Hardie, BA, PhD, Senior Lecturer in Psychology

Christine R Critchley, BA, PhD, Senior Lecturer in Psychology

Faculty of Life and Social Sciences, Swinburne University of Technology, Melbourne, VIC.

Correspondence: ehardie@swin.edu.au

\section{REFERENCES}

1 Clark CC. Trust in medicine. J Med Philos 2002; 27: 11-29.

2 Allsop J. Regaining trust in medicine: professional and state strategies. Curr Sociol 2006; 54: 621-636.

3 Science at WHO and UNICEF: the corrosion of trust [editorial]. Lancet 2007; 370: 1007.

4 Alaszewski A. Risk, trust and health. Health Risk Soc 2003; 5: 235-239.

5 Shore DA. Communicating in times of uncertainty: the need for trust. J Health Commun 2003; 8 Suppl 1: 13-14.

6 Nader C. System offers best and worst of care. The Age (Melbourne) 2007; Nov 14

7 Australian Centre for Emerging Technologies and Society. Swinburne National Technology and Science Monitor. http://www.swinburne.edu.au/lss/acets/monitor.html (accessed May 2008).

8 Hardie E, Critchley C. Community responses to a hypothetical scenario involving genetic profiling for health promotion purposes: trust and other reasons for behavioural intention [abstract]. International Genomics and Society Conference 2008. Genomics and Society: Setting the Agenda; 2008 Apr 17-18; Amsterdam, The Netherlands. http://www.society-genomics.nl/ CSG_Downloads/doc_61784_conferencebook1.4Mb.pdf (accessed Jun 2008).

9 Fowler FJ. Survey research methods. 3rd ed. London: Sage, 2004.

10 American Association for Public Opinion Research. Standard definitions: final dispositions of case codes and outcome rates for surveys. 3rd ed. Lenexa, Kan: AAPOR, 2004.
11 Werts CE, Rock DR, Linn RL, Jöreskog KG. A general method for estimating the reliability of a composite. Educ Psychol Meas 1978; 38: 933938.

12 van der Schee $E$, Braun B, Calnan $M$, et al. Public trust in health care: a comparison of Germany, the Netherlands, and England and Wales. Health Policy 2007; 81: 56-67.

13 Thomas KJ, Nicholl JP, Coleman P. Use and expenditure on complementary medicine in England: a population based survey. Complement Ther Med 2001; 9: 2-11.

14 Millar WJ. Patterns of use - alternative health care practitioners. Health Rep 2001; 13: 9-21.

15 Xue CCL, Zhang AL, Lin V, et al. Complementary and alternative medicine use in Australia: a national population-based survey. J Altern Complement Med 2007; 13: 643-650.

16 Astin JA. Why patients use alternative medicine: results of a national study. JAMA 1998; 279: 1548-1553.

17 Calnan MW, Sanford E. Public trust in health care: the system or the doctor? Qual Saf Health Care 2004; 13: 92-97.

18 Hayward D. The public good and the public services: what role for the private sector? Dissent 2002; Autumn/Winter: 8-12.

19 Hall MA, Dugan E, Zheng B, Mishra AK. Trust in physicians and medical institutions: what is it, can it be measured, and does it matter? Milbank Q 2001; 79: 613-639.

(Received 13 Dec 2007, accepted 20 Mar 2008) 